\title{
CRÍMENES CON DENOMINACIÓN DE ORÍGEN. GLOCALIZACIÓN EN LA NOVELA POLICÍACA NÓRDICA FEMENINA
}

\section{CRIME WITH ORIGIN DENOMINATION. GLOCALIZATION IN THE NORDIC CRIME FICTION BY WOMEN}

\section{Eva PARRA MEMBRIVES}

Universidad de Sevilla membrives2@gmail.com

Resumen: En el seno de la novela negra suele calificarse como nórdica aquella que, elaborada por autores escandinavos, se caracteriza por mostrar ambientes de melancolía y tristeza. Las autoras femeninas sin embargo apuestan por unos contenidos mucho más específicos, que es muestra de una glocalización literaria buscada.

Abstract: The denomination Nordic crime novels usually refers to texts written by scandinavian authors where the sorrowful and melancholic atmosphere pretends to be characteristic of a particular subgenre. Nevertheless, women crime writers seem to prefer more specific contents, which reveal a literary glocal interest. 
Palabras clave: Novela negra femenina. Novela negra nórdica. Glocalización literaria. Yrsa Sigurdarđottir.

Key Words: Women crime fiction. Nordic crime fiction. Literary glocalization. Yrsa Sigurdarđottir.

Entendemos por glocalización, tal como lo definiera el sociólogo canadiense Barry Wellman, «the combination of global conectivity and local activity» (Wellman, 1999: 651) ${ }^{1}$ o, mejor aún, como dijera George Ritzer, «the interpenetration of the global and the local, resulting in unique outcomes in different geographic areas» (Ritzer, 2003: 193) ${ }^{2}$. En el contexto del estudio presente, que desea ocuparse de la novela policíaca nórdica femenina, el concepto se empleará para hacer referencia a aquellos rasgos que le confieren a un texto inserto dentro de las fronteras sistémicas que resultan globalmente reconocibles para el género negro una especificidad local. En este caso no se trata, sin embargo, de descubrir, como ya hiciera Livingston, un modelo que explique el hibridismo necesario entre lo aceptado por el canon literario más selectivo y lo aportado por la cultura popular (Livingston, 2001:150) que se detecta en algunas obras, pues glocal no será aquí de aplicación exclusivamente literaria, sino que se referirá tanto a la identidad cultural como a los parámetros sociales específicos de cada cultura en un sentido más amplio.

En cierto modo, la novela policíaca nórdica - sin entrar ahora en consideraciones de género - ya se define de forma local al emplear en su nomenclatura criterios geográficos y no temáticos, como sí hace la novela criminal hard-boiled ${ }^{3}$ o la novela de ciencia-ficción policial ${ }^{4}$, por ejemplo. Se ha procedido en la crítica de este modo por considerar que en aquellos textos

\footnotetext{
${ }^{1}$ Wellman acuña el término para referirse a la situación, aparentemente paradójica, de estar en contacto a nivel global con el resto del mundo a partir de una ubicación local como es el propio hogar a través de Internet. No obstante, ha venido empleándose en los últimos años en muchos más contextos culturales, como en el de la música (Kim \& Shin, 2010) o la lingüística (Savic, 2010).

${ }^{2}$ Igualmente resulta válida la definición de Brooks y Normore: «a meaningful integration of local and global forces» (Brooks, 2010: 52).

${ }^{3}$ Término de uso común para las novelas norteamericanas situadas en un entorno urbano de inicios de siglo y que se suelen caracterizar por ser «unsentimental, illusionslos, gewalttätig und einsam» (Dietze 1997: 9). Dietze considera estas novelas dotadas de un discurso hipermasculino. Vid. igualmente Sánchez Zapatero (2005: 57-59).

${ }^{4}$ Que combina el género de la ciencia ficción con la investigación policial. Un ejemplo interesante son las novelas de Philipp K. Dick, algunas de las cuales han sido llevadas al cine con considerable éxito.
} 
policiales gestados en los países nórdicos, esto es, Noruega, Suecia, Finlandia, Islandia y también, aunque no es propiamente nórdico, Dinamarca (Hindersmann, 2006b: 7), se dan una serie de características comunes que permiten hablar de un subgénero diferenciado en el seno de la novela negra. Prácticamente todas ellas están presentes en la obra del célebre autor sueco Henning Mankell, que, aunque por supuesto no fue el primer autor nórdico en interesarse por el género, sí logró popularizar esta variante policial a nivel internacional ${ }^{5}$, causando en algunos países, como por ejemplo, en España, un verdadero boom editorial ${ }^{6}$. Las novelas, que, pese a su circunscripción a la literatura de entretenimiento y su aparente huida de la llamada «alta literatura», realizan una cruda disección de la sociedad moderna ${ }^{7}$, suelen estar ambientadas en entornos de dimensiones reducidas, en los que la apariencia idílica esconde, sin embargo, terribles horrores que revelan las más oscuras dimensiones de la condición humana que el llamado estado del bienestar no ha logrado eliminar (Nordberg, 2006: 155). El alejamiento de las grandes urbes sirve, en realidad, a un doble propósito: por un lado, para constatar que no es la corrupción inherente a la alienación del individuo propia de la gran ciudad la que genera el mal en el ser humano, sino que éste es naturalmente malvado, y, por otra, presentar las principales lacras de nuestra sociedad moderna a partir de algunos ejemplos representativos que, por su reducción a un espacio fácil de dominar, puedan resultar cercanos al lector.

Como rasgo sobresaliente de estos textos suele citarse igualmente en la bibliografía especializada un perfil muy concreto de investigador, usualmente perteneciente al cuerpo de policía, masculino, de mediana edad, con problemas familiares tan serios que han contribuido a convertirle en un amargado y malhumorado solitario, consistiendo su vida privada en una mezcolanza de lo que la crítica ha querido llamar «Magengeschwüre und Eheprobleme», es decir, úlceras y problemas matrimoniales (Wopenka 1998: 192; Hagenguth, 2006: 26). Esto, unido a una climatología adversa, lleva a

${ }^{5}$ La dificultad inicial para interesar al público español por la narrativa policial nórdica experimentada por Mankell queda muy bien descrita por Javier Sánchez Zapatero: «Mankell, hoy consagrado autor superventas, adorado por el público y la crítica, merecedor en 2007 del Premio Carvalho, objeto de importantes campañas publicitarias, poseedor incluso de su propio dominio en Internet (http://www.henningmankell.es), dio sus primeros pasos en el mercado editorial español de forma titubeante, sin respaldos publicitarios ni excesiva confianza en la respuesta positiva de los lectores ante su obra» (Sánchez Zapatero, 2010: 72).

${ }^{6}$ Cf. Hindersmann (2006b: 7) y también Hagenguth (2006: 22), que coinciden en atribuirle a Mankell la popularidad de la novela policial escandinava en Europa.

${ }^{7}$ «So politisch wie die nordische Krimiliteratur ist keine andere. Es scheint, als schärfe die Randlage der nordischen Länder die politischen und sozialen Sinne ihrer Krimiautoren» (Gohlis, 2006: 15). 
que se respire a lo largo de estas historias un ambiente profundamente depresivo y de desesperanza que no logrará solucionarse (Müller, 2003: 213) ni siquiera con el aparente restablecimiento del status quo dañado al final de la novela (Schulz-Buschhaus, 1975: 202; Stricker, 2002: 32; Müller, 2003: 230). Tanto Mankell, como su compatriota Håkan Nesser, el islandés Arnaldur Indriđason, el noruego Jo Nesbø y, en menor medida, el también sueco Stieg Larsson, entre muchos otros ${ }^{8}$, comparten esta línea de escritura, convirtiendo lo nórdico en una marca apta para la exportación, al mismo nivel, como indica Hagenguth, que lo fueron en su día o continúan siendo aún ABBA e IKEA (Hagenguth, 2006: 23).

No obstante, como se podrá advertir fácilmente, a excepción del clima, ese persistente frío y la lluvia perenne que logran penetrar en los ánimos de los personajes hasta convertirlos igualmente en gélidos y entumecidos, los rasgos indicados sólo son casualmente nórdicos, esto es, ciertamente coinciden en aquellos autores de procedencia geográfica sobre todo escandinava, pero no pertenecen per se a aquella región. La desesperanza, el detective malhumorado, la dura crítica social, etc. podrían haber sido perfectamente definitorias de textos procedentes de otras latitudes, y, de hecho, el autor Hakan Nesser afirma estar menos interesado en retratar particularidades geográficas en sus novelas que presentar paisajes interiores (Wopenka, 2006: 96). Ninguno de esos rasgos resulta determinante para poder hablar de novelas construidas de forma inequívoca en torno a lo que podría calificarse como un «crimen con denominación de orígen», en este caso nórdico, entendiendo tal etiqueta, a semejanza de la aplicada a los productos agrarios, como «[...] un producto originario de la misma [región geográfica], y cuya calidad o característica se deban exclusivamente al medio geográfico, comprendiendo en éste los factores naturales y los humanos». ${ }^{9}$

Sin plantearse ahora si los autores nórdicos pretenden construir mediante sus escritos un discurso que permita a sus lectores reconocer en él determinadas identidades culturales colectivas ${ }^{10}$ cabría preguntarse si las novelas de Mankell, Nesser y Nesbo, en lo que respecta a las características defini-

\footnotetext{
${ }^{8}$ Hagenguth cita también, en un contexto similar, a Sjowall/Wahlöö, Unni Lindell y Kjell Ola Dahl (Hagenguth, 2006: 26).

${ }^{9}$ Tal como lo define el artículo 156 de la ley de la propiedad intelectual mejicana, ${ }^{10}$ http://www.sice.oas.org/int_prop/nat_leg/Mexico/lipmexsd.asp, que en este caso nos ha parecido más próxima a nuestros objetivos.

${ }^{10}$ En el sentido que le da Assmann, esto es, unos «programas» culturales que permitan la identificación con una identidad cultural colectiva a partir de rasgos determinativos como raza, lengua, religión, o, como en este caso, territorio geográfico común (Assmann, 2006: 219).
} 
torias antes indicadas, son realmente productos cuya calidad o característica se deban exclusivamente al medio geográfico en el que han nacido. Resulta bastante dudoso que así sea, y, de hecho, no es difícil ofrecer una contundente respuesta negativa a la pregunta planteada si sólo se amplía el corpus de textos nórdicos estudiado con algunos de los nombres femeninos más sobresalientes.

Aunque el despertar del interés por el género negro de la mujer fue algo más tardío que el de sus compañeros varones también en el norte de Europa (Nordberg, 2006: 144), en la actualidad son muchos los nombres femeninos que pueden citarse en este contexto, yendo acompañados la mayor parte de ellos con frecuencia por el sobrenombre de «reina del crimen» 0 «dama del crimen» en la prensa o en los blogs temáticos, en los que las reseñas a este tipo de obras ${ }^{11}$ se están multiplicando en los últimos años. Curiosamente, sin embargo, ni Camilla Läckberg, Karin Fossum, Liza Marklund o Mari Jungstedt, entre otras muchas que cabría citar aquí, todas ellas autoras del género negro y de procedencia indudablemente nórdica, adaptan sus escritos al esquema antes referido. Läckberg, por ejemplo, emplea en sus hasta la fecha siete novelas policíacas localizadas en el idílico pueblecito de Fjällbacka, del que la misma autora es oriunda, a la pareja investigadora Patrick Hedström y Erika Falk que, pese a los habituales problemas cotidianos, se describe como un matrimonio estable y feliz. El pesimismo social acusado aparentemente propio de la novela policíaca nórdica (Müller, 2003: 223) también se halla ausente de la obra de Karin Fossum, que emplea en el inspector Konrad Sejer, activo en la ciudad de Oslo ${ }^{12}$, a un hombre ciertamente solitario tras el fallecimiento de su mujer, pero conocido en su entorno por su amabilidad y el amor que le profesa a la familia que le queda. Liza Marklund recurre incluso a una investigadora no profesional, la periodista Annika Bengtzon, de Estocolmo $^{13}$, amante esposa y madre de dos niños de corta edad, además de gran profesional, y, finalmente, Mari Jungstedt crea para sus novelas la figura de Anders Knutas, un policía felizmente casado desde hace más de una década, que completa su familia con dos hijos adolescentes y un gato que observa un comportamiento perruno ${ }^{14}$. La soledad del investigador, ese fracaso en su vida privada que le impulsa a mejorar en la profesional para, como indica Scaggs, sentirse integrado en alguna parte y hallar «social validation th-

${ }^{11}$ Nos referimos a las mujeres nórdicas.

${ }^{12}$ Ubicación, en este caso, no pequeña.

${ }^{13} \mathrm{Vid}$. nota anterior.

${ }^{14}$ La lista puede completarse, por ejemplo, con Helene Tursten y su comisaria Irene Huss (Hagenguth, 2006: 26). 
rough work» (2005: 103), no parece propia de la novela nórdica de manufactura femenina.

Si se ha de aplicar igualmente la etiqueta de lo nórdico a la novela negra femenina, entonces ello deberá ocurrir sobre la base de otros rasgos, diferentes a los expuestos hasta ahora, que permitan hablar, sin embargo, de un subgénero autónomo dentro del sistema literario policial. La novela negra, aunque exige un esquema argumental muy concreto - un crimen, unos sospechosos, una investigación y una resolución del caso-, acepta múltiples variaciones dentro de ese mismo armazón, pues, aunque se han establecido en el pasado diversas normas para encorsetar aún más el género ${ }^{15}$, es frecuente que, sobre todo en los últimos años y dada la importante competitividad creada en el mercado editorial, éstas se ignoren o transgredan intencionadamente a fin de crear textos innovadores (Parra Membrives, 2011) que atraigan la atención del lector (Parra Membrives, 2012). Algunas de las propuestas o bien temáticas o bien estilísticas de las autoras nórdicas, algunos de sus motivos, personajes, hechos o lugares, deberían presentar por ello una desviación lo suficientemente clara o una especificidad lo bastante concreta como para que lo glocal de sus obras sea fácilmente advertible y permita hablar de la presencia en el panorama literario de una novela policíaca nórdica femenina sin que ésta se apoye en un mero resumen de frecuencias argumentales detectadas en los más exitosos textos. Esto es, en los textos policiales deberán encontrarse identificaciones culturales en número suficiente como para que los textos sean tenidos por indudablemente nórdicos. O, volviendo a retomar el ejemplo agrario antes indicado, habría que preguntarse de qué rasgos específicamente nórdicos dotan las reinas y damas del crimen sus novelas y qué puede hallarse en sus textos que confirme una glocalización y justifique el sobrenombre de nórdico para aquellas novelas más allá de la mera procedencia geográfica de sus autoras.

Para responder a la pregunta planteada sirva hoy como objeto de estudio la autora islandesa Yrsa Sigurðardóttir. Aunque Islandia inició su tradición policíaca en fechas algo más tardías al resto de países del frío (Jakobsdóttir, 2006a: 188), en la actualidad cuenta con algunos representantes que han alcanzado un importante reconocimiento internacional (Jakobsdóttir, 2006b: $301)$, entre los que se encuentra, precisamente, Sigurðardóttir ${ }^{16}$. Nacida en la ciudad de Reykjavík, en el año 1963, la autora combina su profesión de in-

${ }^{15}$ Vid. las normas de Knox y Van Dine (Knox, 1947: 194-196).

${ }^{16} \mathrm{La}$ autora ha recibido escasa atención científica en nuestro país, siendo uno de los pocos estudios el de Román (2008), que, no obstante, no la adscribe a la literatura nórdica, sino a la germánica. 
geniera con la escritura, dedicándose a los textos infantiles en un primer instante, y algo más adelante, a partir del año 2005, a su serie policíaca en torno a la pareja de abogados Póra Guðmundsdóttir y Matthias Reich, de la que en la actualidad se han publicado un total de cinco novelas ${ }^{17}$. La primera de ellas, Priðja táknið, conocida en castellano como El último ritual, fue traducida, según indica la publicidad de Suma de Letras, la editorial española, a veinte idiomas ${ }^{18}$. Que, al menos en España, ya en este primer texto se busca la identificación con lo nórdico es evidente por la presentación elegida por la editorial, que en las páginas que preceden a cada uno de los capítulos decide insertar un fondo cubierto de símbolos rúnicos, condicionamiento del lector que, por ejemplo, en la traducción alemana se halla ausente y que sugiere un intento de aprovechamiento por parte de Suma de Letras del interés por lo nórdico generado en España a raíz del éxito editorial de Mankell.

La obra de Sigurðardóttir se caracteriza, contradiciendo lo indicado en algunos textos teóricos para la novela policíaca nórdica ${ }^{19}$, por un fino sentido del humor, no dudando la autora en reírse en algunas ocasiones incluso del acusado feminismo reivindicativo y andrófobo que caracteriza muchos de los escritos de sus compañeras de género ${ }^{20}$, entendido este último término ahora en sentido literario. Así, cuando, recurriendo a los clichés de la novela de detectives del Golden Age británico ${ }^{21}$, su compañero pretende proteger a la protagonista femenina de los escabrosos detalles del crimen que investigan conjuntamente en El último ritual, ésta reacciona rechazando el papel de damisela delicada que se le atribuye, intentando mostrar una imagen de investigadora hard-boiled al puro estilo norteamericano:

—Me temo que esto le va a resultar de lo más desagradable — respondió, volviéndose hacia ella-. Usted no tiene experiencia en este género de cosas y no estoy nada seguro de que esto sea sensato. Lo mejor sería que yo le contase a usted de qué va todo.

Póra entornó los ojos.

- He parido dos hijos con los correspondientes dolores, sangre, placenta, se-

${ }^{17}$ La autora ha publicado una sexta novela con otros personajes.

${ }^{18}$ Según se indica en la solapa.

${ }^{19}$ Vid. «Humor, Esprit gar sind Mangelware» (Gohlis, 2006: 14).

${ }^{20}$ En particular el norteamericano, que surge inicialmente como parodia de unos exagerados modelos masculinos con deseos de autoafirmación a través de la violencia (Dietze, 1997: 210).

${ }^{21}$ Mujeres que no son más que caricaturas en algunos casos, como muy acertadamente indica Sea$\operatorname{man}(2004: 186)$. 
creciones y Dios sabe qué más. Sobreviviré a esto»-Cruzó las piernas y le dio la espalda-. Y usted, ¿qué ha hecho? (Sigurðardóttir, 2006: 67).

No obstante, ni tan siquiera la traumática experiencia femenina del parto logra preparar a Póra Guðmundsdóttir, la abogada protagonista de la serie, para las crueldades del crimen, cuya trivialización las autoras europeas dedicadas al género policíaco - ya sean o no nórdicas - suelen censurar (Parra Membrives, 2010). Apartándose igualmente de la imagen de mujer dura e insensible de la novela negra feminista ${ }^{22}$, que tanto éxito cosecha en los EEUU $^{23}$, una vez enfrentada a los crudos detalles del asesinato, Póra padece un mareo y ha de abandonar la sala, una acción que su compañero comenta de forma burlona:

Cuando salió al pasillo escuchó a Matthew decirle al médico con falso asombro:

—Qué raro, pero si ha parido dos niños (Sigurðardóttir, 2006: 77)

La capacidad de reírse de sí misma como mujer, parodiando al personaje de un género que en sí mismo nació como parodia como lo es el hard-boiled femenino (Keitel, 1998; Seaman, 2004: 186), rechazando los roles tanto tradicionales como los marcadamente masculinos o los insistentemente andrófobos que se le asignan con frecuencia a la mujer en el género policial, sobre todo en el anglosajón, contribuye a convertir a Póra Guðmundsdóttir, el personaje principal de Sigurðardóttir, en un nuevo prototipo de mujer. También Póra, como muchos de los policías protagonistas de los textos nórdicos masculinos, está divorciada, pero lejos de sentirse por ello fracasada y traumatizada, esta abogada islandesa, madre de dos hijos, afronta su compleja situación con un gran sentido del humor. La relación con su ex marido no es especialmente buena, mas la autora no aprovecha tal circunstancia ni para convertir en una amargada a su protagonista ni para apostatar sobre las maldades del género masculino. Comprendiendo que la tensa relación existente

\footnotetext{
${ }^{22}$ A este respecto indica Liza Marklund: «Ich bin eine Frau und wollte Krimis schreiben, weibliche Krimis, in denen die aktuellen Lebensbedingungen von Frauen zur Sprache kommen. Bei anderen Krimiautorinnen und ihren Heldinnen erkenne ich nichts wieder, ich habe nichts mit ihnen gemeinsam. Sie sind immer Single, haben keine Kinder, leben ziemlich trübsinnig und haben kein Geld. Ich kenne gar niemanden, der so ist. Alle meine Freunde haben Kinder oder andere Beziehungen, sie arbeiten zu viel, essen und ficken zu wenig» (citada en Hindersmann 2006a: 251). Por el contrario, la novela femenina hard-boiled insiste en una investigadora solitaria, alejada de las familias tradicionales (Dietze, 1997: 231)

${ }^{23} \mathrm{Vid}$. aquí el excelente estudio de Barnett, que analiza un número amplísimo de personajes femeninos de la novela policíaca (2008).
} 
entre ambos no es más que un producto natural de su distanciamiento afectivo, Póra asegurará en la segunda novela de la serie, Ladrón de almas, ${ }^{24}$ que:

No soportaba tener que pedirle un favor a Hannes, porque sabía que él disfrutaba cuando ella necesitaba hacerlo y, sobre todo, porque a ella le sucedía exactamente lo mismo, pero en sentido contrario (Sigurðardóttir, 2007: 104)

Convirtiendo con ello a su antigua pareja no en el malvado enemigo, sino en un antagonista a quien resulta casi divertido oponerse una y otra vez. Que, pese a todo, su novela merece la clasificación de femenina, lo confirman no sólo los múltiples personajes de tal condición que pueblan los escritos de Sigurðardóttir y a los que se les presta especial atención, sino los crímenes con importantes implicaciones de género que se plantean en los textos: la venganza por el amor ausente de una madre, aunque no es el motivo real del asesinato, llega a posibilitar éste en El último ritual; un supuesto incesto, celos femeninos y el amor protector de una madre por su hija acompañarán las muertes en Ladrón de almas; la venganza por una cruel violación será detonante de los crímenes en Ceniza; y en la violación de una chica en coma, así como el atropello de una joven, casi una niña aún, se centrará también Horfðu á mig, Mírame a mí, aún inédita en castellano. Igualmente, cual suele ser común en las novelas femeninas europeas, en contraposición a las norteamericanas, Sigurðardóttir huye de la descripción detallada de crueldades y torturas, prefiriendo sugerir simplemente lo cruento de los crímenes cometidos, dejando a lo largo del texto múltiples espacios vacíos que el lector habrá de completar por sí mismo con ayuda de su imaginación (Hagenguth, 2006: 43), pero sin recrearse en ciertas atrocidades, que, por supuesto, están presentes en la novela, como sucede, por ejemplo, en El último ritual:

Después de las declaraciones había varias páginas de fotos fotocopiadas, tomadas en el lugar de los hechos. Eran poco claras y en blanco y negro, pero se veía suficiente como para darse buena cuenta del horripilante suceso. En ese momento Póra comprendió todavía mejor la conmoción nerviosa del hombre que encontró el cadáver y se permitió dudar de que pudiera llegar a recuperar plenamente la normalidad algún día (Sigurðardóttir, 2006: 55).

Pero más interesante que la adscripción a la novela policíaca femenina de las novelas de Sigurðardóttir, cuestión que podrá ser analizada más deteni-

\footnotetext{
${ }^{24}$ No confundir con la novela de Ann Benson que fue traducida al castellano con idéntico nombre y gozó de un importante éxito de público.
} 
damente en otro lugar, será sin duda alguna su preocupación por construir textos de configuración glocal. Por supuesto, para ello la autora recurre a una localización geográfica indiscutiblemente islandesa, se lamenta en ocasiones del frío o de la nieve, menciona incluso en alguna de ellas la importante crisis económica y la particular decisión que el gobierno islandés tomó con respecto a la banca, pero todo ello no supone más que utilizar un marco conocido por la autora para situar la acción de su historia (Gohlis, 2006: 21). Donde verdaderamente destaca Sigurðardóttir es en sus crímenes imaginados, que son ciertamente únicos, y, al menos algunos de ellos, indicutiblemente nórdicos.

Aunque tanto el perturbado joven interesado por lo satánico y las persecuciones de brujas en el pasado islandés de El último ritual, como la hija ilegítima, pero rica heredera de una importante familia terrateniente de Ladrón de almas, hallarán la muerte debido a las particulares circunstancias históri$\operatorname{cas}^{25} \mathrm{o}$ administrativas ${ }^{26}$ de este país, no será hasta Ceniza donde el crimen se perfile como indudablemente nórdico y dotado de rasgos específicamente atribuibles a estas regiones. En la novela, Sigurðardóttir aprovecha la alarma social creada con ocasión de la erupción del volcán Grimsvötn en noviembre del 2004, temor que se repetiría con posterioridad a la publicación de su novela a nivel internacional, debido a nuevas actividades volcánicas, creando importantes perturbaciones incluso en el tráfico aéreo y que posibilitarán la identificación de la trama argumental con lo islandés también para los lectores de las traducciones, posteriores en fecha, de este texto. La acción está situada en el año 2007, pero los crímenes investigados inicialmente parecen haberse producido varias décadas atrás, con ocasión de otra erupción volcánica, en este caso la del volcán de la isla de Heimaey, que, tal como queda reflejado en el texto, inició su actividad en enero de 1973. Utilizando este hecho real como marco histórico y la pequeña isla de Heimaey como ubicación geográfica para su novela, la autora imagina un crimen que aprovecha precisamente la particularidad islandesa de vivir cruentos fenómenos naturales para poder pasar desapercibido. A la hora de rehabilitar algunas de las casas cubiertas de ceniza, que, sin embargo, no quedaron totalmente destruidas, los equipos de excavación hallan unos restos humanos que parecen pertenecer a unos hombres salvajemente asesinados. La investigación inicial apunta a que el asesino decidiera aprovechar la desgracia padecida por los habitantes de la isla para ocultar su acción, trascendiendo así el volcán su papel de mero

\footnotetext{
${ }^{25}$ La caza de brujas.

${ }^{26}$ Las leyes que regulan herencias y sucesiones.
} 
escenario y convirtiéndose en cómplice activo del delito, eliminando huellas incriminatorias:

[...] sí que recuerdo que en los momentos decisivos hubo aquí trescientos o cuatrocientos hombres trabajando en el salvamento -Kjartan miró a Póra a los ojos - . Si me estás preguntando si alguno de ellos puede haber entrado en la casa a dejar allí los cadáveres o a matar allí a aquella gente, la respuesta, sin duda alguna, es que sí. Más aún, se puede decir que no existía la más mínima dificultad. Esas casas que están excavando ahora no desaparecieron enseguida bajo las cenizas. Pasaron por lo menos dos semanas desde el principio de la erupción hasta que las cubrió la ceniza. En realidad, dudo que yo mismo me hubiera atrevido a entrar alli en aquellos momentos, por la proximidad del cráter, pero es posible que alguien fuera lo suficientemente insensato como para hacer algo así. Quedaron enterradas bajo lava en torno a las cuatrocientas casas, y en ésas, naturalmente, no hubo posibilidad de salvar nada. Pero esa fila de casas quedó cubierta de ceniza, que no acarrea la misma destrucción que una lengua de lava ardiendo. Si yo hubiera tenido que deshacerme de unos cadáveres habría elegido una casa que fuera a quedar cubierta por la lava, aunque para ello habría hecho falta una buena dosis de coraje. La lava no se desplaza muy deprisa, pero pocas cosas hay más terroríficas que observar esa masa burbujeante que no se detiene ante nada (Sigurðardóttir, 2010: 58).

La situación de emergencia creada contribuirá a oscurecer la clarificación del crimen, pues, pese a que el macabro hallazgo se ha producido en una vivienda determinada, el caos de aquellos días hubiera permitido el acceso a ella de cualquier persona interesada en esconder su culpabilidad y no permite, por tanto, implicar a los ocupantes habituales:

-Era vuestra casa, y me parece improbable que alguien la forzara para entrar y esconder unos cadáveres.

- ¿Que la forzara? -Markús repitió las palabras de Póra-. No había ninguna necesidad de forzar una casa. No había nada cerrado con llave. Se pidió a la gente que no cerrara las casas con llave para que los del equipo de rescate pudieran entrar y salir según necesitaran — se le alegró el semblante- Naturalmente, después de la noche de la erupción todo se llenó de forasteros. No sé el número, pero el trabajo de rescate exigió mucha mano de obra y solo [sic] una pequeña parte de los que se hicieron cargo eran de la isla. Nuestra casa no quedó cubierta de ceniza enseguida (Sigurðardóttir, 2010: 33).

Aunque, finalmente, el asesinato en Ceniza se revelará como una comprensible represalia familiar tras la salvaje violación de una niña, a pesar de 
ser éste un motivo universal, presente en textos de todo tipo de procedencia geográfica y no precisamente exclusivo de la novela negra nórdica, la forma de construir el escenario del delito le confieren unos rasgos locales tan específicos a este asesinato, que puede hablarse perfectamente de un crimen glocal. Pues global es la sed de venganza del padre que ha comprobado la vejación de su hija, global puede ser la emasculación del violador por parte del joven secretamente enamorado de la chica, mas la idea de ocultar el cadáver mutilado en una vivienda que quedará cubierta para toda la eternidad por las cenizas volcánicas no puede suceder sino en Islandia, y le aporta el colorido local necesario para poder hablar en este caso de la combinación perfecta entre lo local y lo global que permitirá la aparición de un crimen glocal.

El interés por los crímenes glocales, por elaborar textos con denominación de orígen, indicutiblemente nórdicos, con todas las connotaciones que pueden ser asociadas a tales términos, se demostrará en la autora también en textos posteriores, revelando que el empleo de rasgos específicamente islandeses como definitorios de su crimen no fue casual. En la misma línea construye Sigurðardóttir su cuarta novela, Auðnin, Desierto, aún inédita en castellano, y situada esta vez en la próxima Groenlandia y en un entorno esquimal. También aquí el escenario es dantesco: la desaparición de una geóloga durante unas perforaciones mineras en un paisaje nevado se complica con la sucesión de unas muertes horribles. Por supuesto, como no podía ser de otro modo, las inclemencias del tiempo dificultan la investigación y se insiste mucho en ellas a lo largo de la novela, acompañando en todo momento a los personajes, pues serán fundamentales a la hora de ocultar la causa de las misteriosas muertes acaecidas.

Interesante resulta la indefensión que le produce al equipo investigador el hallarse completamente aislado en mitad de un paisaje nevado, pues convierte paradójicamente esta novela emplazada en un espacio que no puede ser más abierto - los parajes nevados de Groenlandia - en una típica historia del tipo locked room al mejor estilo de Agatha Christie. Pues cuando, tras desplazarse Póra y Matthias junto a algunos miembros de la compañía inversora al campamento de explotación minera groenlandés para aclarar el motivo de algunas desapariciones, quedan todos aislados debido a un fuerte temporal, el escenario pasa a recordar las novelas de detectives del Golden Age británico.

Reducido el número de actantes posibles en la historia, debido a las circunstancias climatológicas tan extremas, ha de ser necesariamente alguno de 
los escasos personajes situados por la autora en aquel emplazamiento - que, al margen de los recién llegados, incluye también un pequeño asentamiento esquimal - los que se deban responsabilizar de los crímenes que van sucediéndose en la novela. Todos, excepto la pareja protagonista, por supuesto, serán sospechosos, como en toda buena novela de espacios cerrados, y, al igual que suele suceder en este tipo de narración, va mermando cada vez más el número de culpables potenciales a medida que avanza la historia, pues se procede a la violenta eliminación de quienes más probabilidades poseían de ser identificados por los lectores como asesinos. Esta técnica, en la que las sucesivas muertes eliminan sospechosos, apenas se emplea hoy en día al margen de los textos comúnmente conocidos como locked room. Interesada más en resolver las causas sociales que conducen hacia la violencia que en plantearle al lector un complejo acertijo que ha de resolver, la novela policíaca contemporánea, incluyéndose por supuesto aquí la variante femenina del género, no necesita mantener la atención lectora impactando en su público una y otra vez con las muertes sucesivas de los principales sospechosos para que éstas desconcierten a los receptores del texto en su concepción de cómo debieron producirse los hechos narrados. El traslado del centro de atención del cómo ocurrió el crimen al por qué se produjo éste exigido por el lector más moderno ${ }^{27}$ significó la reducción drástica en el seno del género policial de novelas de espacios cerrados en pro de nuevas formas de narración criminal. Sin embargo, Sigurðardóttir no parece hallar dificultad alguna en seguir insistiendo en un modelo que logrará demostrar convincentemente que en absoluto ha quedado obsoleto. Antes al contrario, la autora dota al esquema tradicional de unos condicionantes típicamente nórdicos a partir de un esquema tradicional y muy general, logrando esa acertada combinación entre lo local y lo global que conducirá a un texto indicutiblemente glocal.

Ya la idea de convertir la inmensidad nevada groenlandesa en una habitación cerrada a efectos investigadores ha de considerarse, además de original e innovadora, específicamente glocal, pues se aprovecha un esquema global - la estructura locked room - para dotarla de unos contenidos locales - un campamento groenlandés emplazado en mitad de la nieve- muy concretos. Pero la autora subraya aún más con un guiño casi humorístico la antítesis creada por aquello que, no limitado por horizonte alguno, ha de identificarse sin embargo con un pequeño claustro amurallado. Al titular una historia que se desarrolla íntegramente en la nieve Аuðnin, Desierto, llega a suscitar unas expectativas muy determinadas en las mentes lectoras, que no

${ }^{27}$ Por sus múltiples implicaciones sociales. 
se cumplirán, o, al menos, les costará a los lectores reconocer inicialmente en los contenidos del texto, pues Desierto les hará muy probablemente imaginar otros parajes que los groenlandeses. Sin embargo, ese desierto helado al que se enfrentan los personajes, ese entorno local tan concreto que es descrito con especial detenimiento a lo largo de la novela, en cuanto a paisaje solitario, abandonado, y alejado de toda civilización, desértico, en definitiva, como sugiere la autora, contiene implicaciones globales muy evidentes.

Precisamente, la idea de lo glocal, es decir, insístase ahora, de la acertada combinación de lo global con lo local, se revela claramente en la elección del título del texto: local es aquí el campamento nevado groenlandés, local es la tormenta de nieve que impide las comunicaciones con el exterior y la aproximación de la civilización, local es el pequeño asentamiento esquimal, sin duda alguna. Pero lo que implica aquí la selección del vocablo Desierto - y no, por ejemplo, Hielo $^{28}$-, esto es, todo lugar susceptible de convertirse en un espacio cerrado en un momento dado por la ausencia de seres humanos próximos, es claramente global: desde las arenas saharianas a la selva amazónica, las montañas en el Himalaya e incluso algún pueblo americano minúsculo, todos estos escenarios podrían convertirse en un momento dado en desiertos. La paradójica selección de un título que sugiere en las mentes lectoras calidez, sol y arena para un paisaje helado, obedece así a la intención de señalar lo globalizado de lo local descrito, esto es, de construir un escenario glocal. Existen múltiples formas desérticas, nos indica la autora, y en este texto se abordará una muy específica de ellas, la variante propiamente nórdica, de la que Sigurðardóttir se erige en representante.

Por supuesto, debido a ello, la autora también insistirá en describir con todo detalle las particularidades propias de ese desierto elegido por ella como escenario de su novela y que contará con unos rasgos que revelarán su exclusividad nórdica. El aislamiento de los personajes será absoluto no tanto por la distancia espacial existente entre la ubicación del campamento y cualquier otro centro habitado, sino por la imposibilidad de acceder al lugar de los hechos por tierra o aire por darse unas condiciones climatológicas tan adversas que por sí mismas ya pueden resultar mortales. De hecho, la desaparición de la geóloga que desencadena la acción de la historia y que ocupará el primer capítulo del texto, será, en un primer momento, explicada por el exterior no como un crimen, cuya autoría no ha quedado resuelta, sino como un accidente

${ }^{28}$ En su traducción al alemán se eligió el título de Die eisblaue Spur, esto es, la huella azul hielo, lo que revela que se priorizó cumplir con las expectativas lectoras, sin comprender la intencionalidad glocal de la autora. 
precisamente producto del mal tiempo. Considerándose que la joven salió a pasear, siendo sorprendida por una repentina tormenta, aunque se cree segura su muerte, no se busca responsabilidad humana en ésta. El particular entorno en el que se sitúa la acción, en este caso Groenlandia, funciona de nuevo como cómplice del delito, permitiéndole al asesino quedar - al menos inicialmente - impune y disfrazar un asesinato de desgraciado accidente. Al igual que en Ceniza, la autora se valió de la ayuda del volcán para eliminar huellas y proteger a los culpables de los crímenes por ella imaginados, en $D e-$ sierto protege a sus delincuentes mediante la nieve y la tormenta. Una complicidad que, sin duda, sólo puede darse por supuesto en un entorno nórdico.

Aunque todo lo antes indicado ya sería suficiente para demostrar el interés de Yrsa Sigurðardóttir por construir sus novelas criminales dotándolas de rasgos específicamente nórdicos, Desierto cuenta sin embargo con un crimen añadido, que es, de todos los hasta ahora imaginados por la autora islandesa, el que más nórdico se ha de antojar a sus lectores.

Avanzado el relato aparecen muertos varios científicos que se daban por desaparecidos, y junto a ellos, el horriblemente mutilado cadáver de un desconocido. La imaginación de los investigadores se dispara y las suposiciones de cómo ha podido llegar a producirse tan cruento escenario son diversas. Sin embargo, sólo el nevado paisaje groenlandés podía haber permitido la solución planteada finalmente por la autora.

El hombre desconocido se logra identificar como un esquimal fallecido a principios del siglo anterior a causa de un mal vírico que igualmente acabó con todo su pueblo. Intentando huir de un destino que conceptuaba como una maldición de los dioses, el desgraciado esquimal, enfermo de gravedad, intentó escapar huyendo a través de la nieve, quedando sepultado por ésta en el mismo lugar donde, tras caer agotado, halló la muerte. Que fuese ese punto precisamente el elegido por unos geólogos para perforar en busca de minerales es producto de la casualidad o, si así se quiere, de nuevo del destino, o quizá supone la venganza de la naturaleza helada que rechaza el avance civilizado. Para terror de los geólogos, la pesada maquinaria empleada en las perforaciones exploratorias buscó el camino hacia las profundidades de la tierra atravesando el vientre del esquimal fallecido muchos años atrás. Y es a partir de aquí donde Sigurðardóttir imagina su crímen nórdico, su delito con denominación de origen. Pues, pese a pertenecer a una época muy distante en el tiempo, el esquimal infectado se ha conservado en la nieve en tan perfectas condiciones, que permite a su virus mortal infectar, a través de los años, a los geólogos que recuperarán su cadáver de la nieve. La muerte de és- 
tos, que durante páginas y más páginas del relato se supondrán producto de una venganza esquimal por haber el hombre civilizado mancillado sus terrenos sagrados, se revela como un desgraciado accidente, no existiendo más criminal que la inclemente naturaleza. Que el pueblo esquimal quedara prácticamente erradicado muchos años atrás por la llegada del hombre blanco, que dejó allí, en aquel entorno salvaje y resguardado de la civilización, el mortal virus tras una breve visita, y que el último de sus miembros, aún a través de los años, lograra vengar todas aquellas muertes inocentes cediendo de nuevo la ponzoña maldita a los herederos de aquella primera expedición blanca, aniquilándolos a su vez, debe entenderse como esa justicia más allá de la intervención humana en la que la autora suele creer e introducir en sus relatos, causando escalofríos de terror a sus lectores. Cuestiones como ecologismo, destrucción de la naturaleza y venganza de esa misma naturaleza subyacen, y no son nada nuevo en la literatura policial nórdica, pues ya se habían podido ver en la señorita Smilla de Peter Hoeg, un texto igualmente con presencia groenlandesa, en la que la naturaleza se rebela ante la destructiva civilización, resultando, finalmente, vencedora frente a ésta (Bremer, 1999), y demostrando que es imposible vencer al hielo.

En cualquier caso, e independientemente de si Sigurðardóttir se plantea, siguiendo la tradición melvilliana (Bremer, 1999) una exaltación de la más agreste naturaleza como fuerza superior a lo creado por el hombre, es evidente que la autora busca, en sus textos policiales, dotar su suspense criminal de algunos rasgos que sólo pueden ser nórdicos. Nieve, frío y tormenta le resultaban a la autora un recurso demasiado fácil, aparentemente demasiado manido para insertar su obra dentro de una corriente literaria determinada. Con el exquisito cuidado puesto en identificar tanto crimen como criminales, sospechosos como lugar del crimen, arma homicida como cómplices con cuestiones nórdicas exclusivistas, ha logrado proporcionarle un nuevo valor a tal etiqueta en el ámbito de la novela negra. Que este esfuerzo provenga de la novela nórdica femenina supone, simultáneamente, un éxito y una satisfacción para la literatura y la historia estética femenina contemporánea.

\section{REFERENCIAS BIBLIOGRÁFICAS}

ASSMANN, A. (2006). Einführung in die Kulturwissenschaft. Grundbegriffe, Themen, Fragestellungen. Berlin: Erich Schmidt.

BARNETT, C. (2008). Mystery Women: An Encyclopedia of Leading Women Characters in Mystery Fiction. Scottsdale: Poisoned Pen Press. 
BREMER, A. (1999). Kriminalistische Dekonstruktion. Zur Poetik der postmodernen Kriminalromane. Würzburg: Königshausen \& Neumann.

BROOKS, J. S \& NORMORE, A. H. (2010). «Educational Leadership and Globalization: Literacy for a Glocal Perspective». Educacional Policy 24.1, 52-82.

DIETZE, G. (1997). Hardboiled Woman. Geschlechterkrieg im amerikanischen Kriminalroman. Hamburg: Europäische Verlagsanstalt.

GOHLIS, T. (2006). «Nord ist Mord: Ein Streifzug durch die nordische Kriminalliteratur». En Fjorde, Elche Mörder. Der skandinavische Kriminalroman, J. Hindersmann (ed.), 11-21. Wuppertal: NordPark.

HAGENGUTH, A. (2006). «Der Mord, der aus der Kälte kommt: Was macht skandinavische Krimis so erfolgreich?». En Fjorde, Elche Mörder. Der skandinavische Kriminalroman, J. Hindersmann (ed.), 22-52. Wuppertal: NordPark.

HINDERSMANN, J. (2006a), «Schwedens neue Kultfigur: Liza Marklunds Romane über Frauen, Macht und Gewalt«. En Fjorde, Elche Mörder. Der skandinavische Kriminalroman, J. Hindersmann (ed.), 245-265. Wuppertal: NordPark.

- (2006b). «Vorwort». En Fjorde, Elche Mörder. Der skandinavische Kriminalroman, J. Hindersmann (ed.), 7-10. Wuppertal: NordPark.

JAKOBSDÓTTIR, K. (2006a). «Eiskalte Morde auf der eisigen Insel: Eine Geschichte der isländischen Kriminalliteratur». En Fjorde, Elche Mörder. Der skandinavische Kriminalroman, J. Hindersmann (ed.), 188-200. Wuppertal: NordPark.

- (2006b). «Krimineller Einblick in die isländische Gesellschaft: Die Kriminalromane von Arnaldur Indriðason». En Fjorde, Elche Mörder. Der skandinavische Kriminalroman, J. Hindersmann (ed.), 301-210. Wuppertal: NordPark.

KEITEL, E. (1998). Kriminalromane von Frauen für Frauen. Unterhaltungsliteratur aus Amerika. Darmstadt: Wissenschaftliche Buchgesellschaft.

KIM, P. H. \& SHIN, H. (2010). «The Birth of 'Rok': Cultural Imperialism, Nationalism, and the Glocalization of Rock Music in South Korea, 1964-1975». East Asia Cultures Critique 18.1, 199-230. 
KNOX, R. A. (1947). «A detective story decalogue». En The Art of the Mystery Story, H. Haycraft (ed.), 194-196. New York: Grosset \& Dunlap.

LIVINGSTON, R. E. (2001). «Glocal knowledges: Agency and place in literary studies». PMLA: Publications of the Modern Language Association of America 116 1, 145-157.

MÜLLER, H. (2003). «'Vad är det för värld vi lever i?’ Henning Mankells Konzept des gesellschaftskritischen Kriminalromans». Tijdschrift voor Skandinavistiek 24.2, 199-234.

NORDBERG, N. (2006). «Mord unter der Mitternachtssonne: Eine Geschichte der finnisch-schwedischen Kriminalliteratur». En Fjorde, Elche Mörder. Der skandinavische Kriminalroman, J. Hindersmann (ed.), 118155. Wuppertal: NordPark.

PARRA MEMBRIVES, E. (2010). «Víctimas infantiles. Incapacidades familiares como favorecedoras del mal en Der Kindersammler de Sabine Thiesler». Revista de Filología Alemana 18, 199-219.

- (2011). «Transgresiones lícitas y contravenciones subversivas. Nuevas formas en la novela policíaca femenina europea actual». AEF XXXIV, 175-189.

- (2012). «Treffende Titel. Kulturelle Anpassung bei Vermittlung (Übersetzung) von Kriminalromanen». En Aspects of Literary Translation, E. Parra Membrives; M. Á. García Peinado y A. Classen (eds.), 141-158. Tübingen: Gunter Narr.

RITZER, G. (2003). «Rethinking Globalization: Glocalization/Grobalization and Something/Nothing». Sociological Theory 21.3, 193-209.

ROMÁN PRIETO, M. (2008). La novela policíaca germánica escrita por mujer y hombres. «El último ritual» de Yrsa Sigur冈ardottir en contraste con «La quinta mujer» de Henning Mankell. Norderstedt: Grin.

SÁNCHEZ ZAPATERO, J. (2005). «Novela policíaca y sociedad: Modelos de investigador y condicionamientos socioculturales». En Informe confidencial. La figura del detective en el género negro, A. Martín Escribà y J. Sánchez Zapatero, Javier (eds.), 49-65. Valladolid: Difácil.

- (2010). «Henning Mankell y la saga Wallander: una mirada a la amenaza criminal del Estado del Bienestar». En Realidad y Ficción criminal. Dimensiones narrativas del género negro, J. Sánchez Zapatero y Á. Martín Escribà (eds.), 71-98.Valladolid: Difácil. 
SAVIĆ, J. D. (2010). «Glocalization and Bilingual Language Practices». En Identity Issues: Literary and Linguistic Landscapes, V. Lopičić y B. M. Ilić (eds.), 139-155. Newcastle upon Tyne: Cambridge Scholars.

SCAGGS, J. (2005). Crime Fiction. London: Routledge.

SCHULZ-BUSCHHAUS, U. (1975). Formen und Ideologien des Kriminalromans. Ein gattungsgeschichtlicher Essay. Frankfurt am Main: Athenaion.

SEAMAN, A. C. (2004). «Cherchez la Femme: detective fiction, women, and Japan». Japan Forum 16 (2), 185-190.

SIGURĐARDÓTTIR, Y. (2006). El último ritual. Madrid: Suma de Letras.

- (2007). Ladrón de almas. Madrid: Suma de Letras.

- (2010). Ceniza. Madrid: Suma de Letras.

STRICKER, S. (2002). Wallanders Welt. Konzept und Konstruktion der Kriminalromane Henning Mankells (unveröffentlichte Magisterarbeit, Münster).

TRAUB, R. (1999). «Der Spiegel des Verbrechens». Der Spiegel 26.

VAN DINE, S.S. (1947). «Twenty Rules for Writing Detective Stories». En The Art of The Mystery Story, H. Haycraft (ed.), 189-193. New York: Grosset \& Dunlat.

WELLMAN, B . \& HAMPTON, K. (1999). «Living Networked On and Offline». Contemporary Sociology 28.6, 648-654.

WOPENKA, J. (1997). «Morden im kalten Norden». En Das Mordsbuch. Alles über Krimis, N. Schindler (ed.), 188-194. Frankfurt am Main: Gutenberg.

WÜLLENWEBER, W. (2001). «Wallanders Welt». Der Stern 25, 68.

Recibido el 6 de mayo de 2012.

Aceptado el 30 de septiembre de 2012. 
